\title{
Tribology of Hip Joints \\ from Natural Hip Joints, Cartilage Substitution, Artificial Replacements to Cartilage Tissue Engineering*
}

\author{
Zhongmin JIN $^{* *}$, Sophie WILLIAMS ${ }^{* *}$, Joanne TIPPER $^{* *}$, Eileen INGHAM ${ }^{* *}$ \\ and John FISHER ${ }^{* *}$ \\ **Institute of Medical and Biological Engineering, \\ School of Mechanical Engineering, University of Leeds, Leeds LS2 9JT, UK \\ Email: z.jin@leeds.ac.uk
}

\begin{abstract}
Tribology of hip joints is reviewed, covering a full spectrum from natural hip joints to total hip replacements, as well as tissue engineered articular cartilage. The importance of integrated tribological studies of contact mechanics, friction, wear and lubrication, as well as fully coupled with biological considerations, has been emphasized. The exact lubrication mechanism in natural hip joints is still not clear, although the unique biphasic characteristics of articular cartilage play an important role. Tribological studies of bearing surfaces for artificial hip joint replacements are important in developing and optimizing alternative material combinations to conventional polyethylene. Recently developed tissue engineered articular cartilage has been shown to be inadequate as far as the tribological property is concerned.
\end{abstract}

Key words: Biotribology, Articular Cartilage, Hip Joint, Artificial Hip Replacement, Tissue Engineering

\section{Introduction}

Natural hip joints are remarkable bearings in engineering terms. The bearing materials are articular cartilage, supported by subchondral bones and lubricated by synovial fluid. The load experienced in hip joints during normal steady walking can reach up to three to five times bodyweight, while a wide range of motions are encountered. The healthy hip joint can last for more than 70 years with minimum friction and wear. However, diseases or trauma can severely impair the normal function of the hip joint, resulting in the loss of articular cartilage and consequently causing pain and restricted movement. Sometimes, the diseased or damaged hip joints have to be replaced by artificial materials, in a procedure referred to as total hip arthroplasty. Such a surgical technique has been shown to be one of the most successful treatments of hip joint diseases developed in the last fifty years. Currently, there are about 1 million hip joint replacement operations carried out world-wide annually. One of the dominant types of these medical devices takes the form of an ultra high molecular weight polyethylene (UHMWPE) acetabular cup against a metallic or ceramic femoral head as shown in Figure 1. The majority of artificial hip joints employing such a material combination fail after 10 to 15 years in the body, as a result of loosening ${ }^{(1)}$. It is now generally accepted that the loosening is caused by adverse tissue reactions to particulate debris, mainly generated at the articulating surfaces. Therefore, understanding of the tribology of the bearing surfaces and the biological tissue reactions to wear debris plays an important role in prolonging the life span of artificial hip joints.

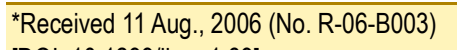
[DOI: 10.1299/jbse.1.69] 


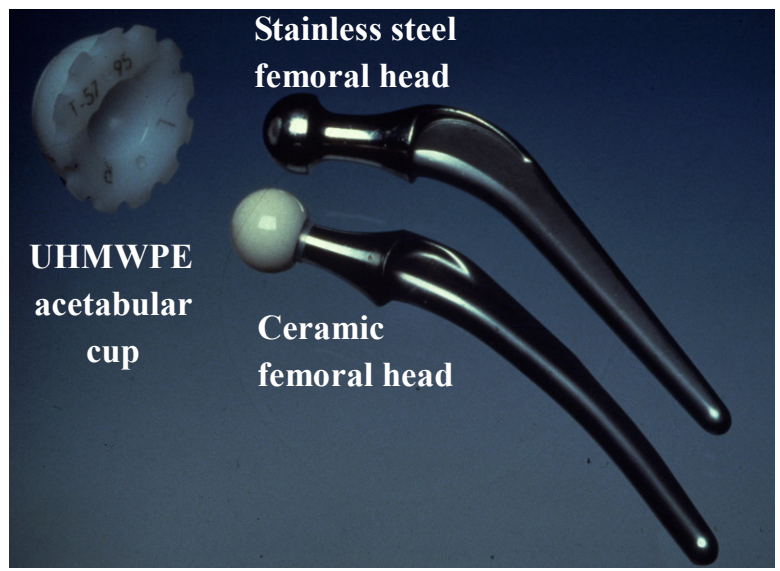

Fig. 1 Typical artificial hip joints with UHMWPE-on-metal and UHMWPE-onceramic material combinations
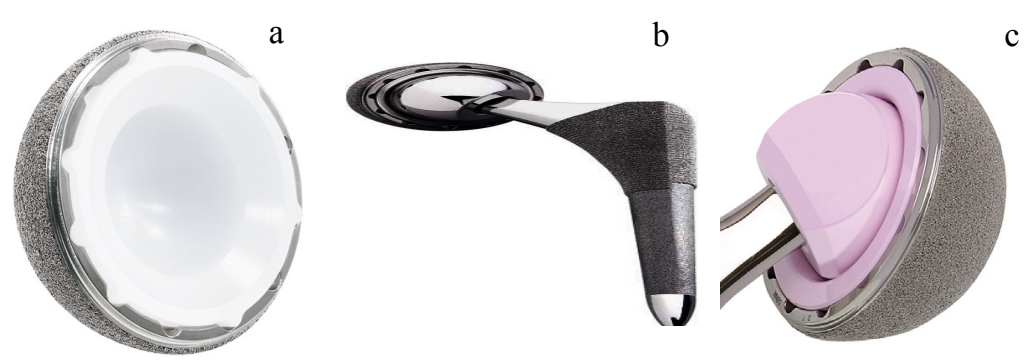

Fig. 2 Alternative forms of artificial hip joints (a) Crosslinked polyethylene liner in a Titanium shell (Marathon liner in Pinnacle shell, DePuy International Ltd, Leeds, UK); (b) Ultamet ${ }^{\circledR}$ metal-on-metal total hip replacement (Ultamet liner in Pinnacle shell and Ultamet head, DePuy International Ltd, Leeds, UK) and (c) Ceramax ${ }^{\circledR}$ ceramic-on-ceramic total hip replacement (Biolox Delta liner in Pinnacle shell and Biolox Delta head, DePuy International Ltd, Leeds, UK)

The clinical limitation of current artificial hip joints of 10 to 15 years puts serious restriction to the use of these devices in young and active patients, with life expectancy after surgery in excess of 25 years. Currently, there are two broad strategies to avoid revision. One is to improve conventional polyethylene total joint replacements by using novel bearing couples to reduce wear and wear particle generation, and this should extend the clinical lifetime of the implant. Examples include the use of highly cross-linked UHMWPE, metal-on-metal and ceramic-on-ceramic combinations as illustrated in Figure 2.

The use of these novel bearing couples is further complemented by the more recent introduction of minimally or less invasive and conservative bone preserving surgeries such as surface replacement hips ${ }^{(2)}$ as shown in Figure 3. While these approaches maintain more bone stock, which makes a subsequent operation easier, as total joint replacements, they continue to replace articular cartilage on both sides of the articulation. Furthermore, the long-term clinical outcome of these alternative bearings beyond 30 years remains unclear, and there are still a number of long-term clinical concerns. These include the systemic transport of metallic ions and potential metabolic, immunologic, or carcinogenic toxicity of metallic elements for the metal-on-metal articulation ${ }^{(3)}$ and long-term stability and potential fracture of ceramic components. The alternative strategy is to develop biological solutions through tissue engineering approaches using cells, scaffolds and bioactive factors ${ }^{(4)}$. 


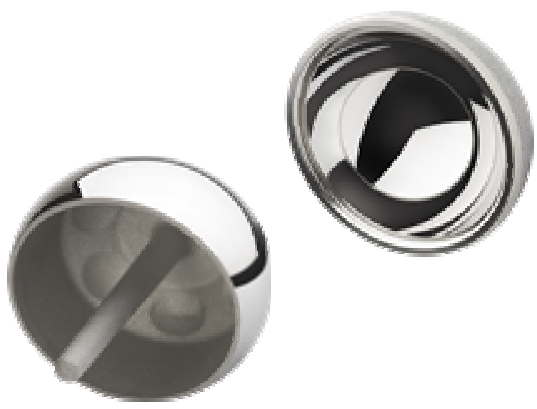

Fig. 3 A typical metal-on-metal hip resurfacing prosthesis (ASR ${ }^{\circledR}$ from DePuy International Ltd, Leeds, UK)

Although these biological solutions offer a long term hope, currently they are not widely used in clinics due to a lack of biomechanical function, failure of integration, and economic and regulatory barriers to commercial realisation. Consequently, there are emerging interests in earlier intervention approaches, which attempt to retain some or all of the functional articular cartilage. These treatments are made feasible by the possible early detection of the onset of the cartilage degradation using recently developed imaging technologies and computer guided surgery. Typical examples include viscosupplementation, hemi surface replacement, spacer technology, cartilage substitution, defect repair systems, self assembling gels and cell transfer. The main goal in these approaches is to delay further progression of cartilage degeneration, whilst relieving pain and restoring function, and to prolong the time before the end-stage total joint replacement.

The aims of this review will focus on the tribology of the bearing surfaces of both natural hip joints and various therapeutic options, covering the whole spectrum from natural tissues to end-stage total hip replacements. Studies of the biological reactions to wear debris ${ }^{(1)}$ and clinical performance are equally important. These topics have been extensively covered elsewhere and will not be addressed in this review.

\section{Tribological Methodology}

Tribology is defined as "the branch of science and technology concerned with interacting surfaces in relative motion and with associated matters as friction, wear, lubrication, and the design of bearings" (Oxford English Dictionary). It is therefore important to address friction, wear and lubrication in an integrated tribological study.

Friction, wear and lubrication are closely linked. Friction often indicates the lubrication regime involved. Lubrication analysis can often help to reduce friction and wear. Both experimental and computational approaches have been adopted to investigate the tribological problems in hip joints. For example, friction and wear are usually studied experimentally while lubrication can readily be modelled computationally. Both simple screening devices and whole hip joint simulator models have been developed. The bearing specimens are often simplified in order to facilitate the tribological studies of the natural hip joint, for example, using cartilage against a biomaterial, although such a configuration is also directly applicable to hemi-arthroplasty.

Coupled tribological and biological approaches are generally required for the study of hip joints. Tribological studies provide inputs of wear debris required for the investigation of biological reactions to wear debris. Studies of biological reactions to wear debris are equally important and can often differentiate further different tribological systems. Furthermore, the biological environment, under which tribological studies are conducted, is becoming more important for the study involving natural articular cartilage and tissue-engineering. Equally important is the tribology system, which may be used as a bioreactor for tissue engineering of cartilage $e^{(5,6)}$. 


\section{Major Findings}

\subsection{Tribology of Natural Hip Joint}

\subsubsection{Summary}

The development of our present understanding of natural hip joint lubrication has proved to be a long and difficult process. The first reference to this subject was made by Sir William Hunter ${ }^{(7)}$. Numerous studies have since been devoted to the understanding of the tribological mechanism in natural hip joints using both experimental and computational approaches. Extensive experimental measurements of friction $^{(8)}$ and computational simulation of lubrication ${ }^{(9)}$ have been carried out in order to understand the lubrication mechanism. However, relatively little has been studied in regard to the wear of cartilage.

Many lubrication theories have been proposed for natural hip joints. These include conventional engineering forms such as hydrodynamic, elastohydrodynamic (on both macro and micro scales ${ }^{(9)}$ ), squeeze film and boundary lubrication ${ }^{(10,11)}$, as well as unique mechanisms pertaining to articular cartilage such as weeping, boosted, floating, ultrafiltration, electrostatic, biphasic, protein-hyaluronic acid network etc ${ }^{(12)}$. Despite these efforts, the exact lubrication mechanism in natural synovial joints is still not clear. It is probably reasonable to assume that a combination or multi-mode of the above mentioned individual forms of lubrication, rather than a single one exists, to provide a remarkable tribological performance of articular cartilage in synovial joints ${ }^{(13)}$.

\subsubsection{Biphasic Lubrication of Articular cartilage}

The importance of the unique biphasic characteristics of articular cartilage has long been recognised in the lubrication of synovial joints, in the form of both weeping and boosted lubrication theories proposed by $\mathrm{McCutchen}^{(14)}$ and Walker et $\mathrm{al}^{(15)}$, respectively. A more general biphasic lubrication theory was subsequently proposed by Mow and Lai ${ }^{(16)}$. However, it was not until in the late 1990s that both friction and interstitial fluid pressurisation were comprehensively addressed ${ }^{(17-19)}$. Extensive friction studies have been carried out under a wide range of tribological conditions to investigate the biphasic lubrication of articular cartilage. Under both start-up and reciprocating motions of a cartilage plug against a metallic counterface, friction was found to increase with loading time $^{(17,20)}$. This was confirmed in a whole joint model study conducted by Mabuchi et al ${ }^{(21)}$. The transient friction behaviour observed is a direct result of the interstitial fluid pressurisation and fluid load support, which was directly measured experimentally ${ }^{(19,22)}$. Such an action can be further enhanced by the inhomogeneous and non-linear tensile and compressive properties of cartilage ${ }^{(23)}$. However, for a similar configuration but under cyclic loading, friction was found to be similar or even at a higher level ${ }^{(24)}$. The importance of a migrating contact area and fluid re-hydration in reducing friction was firstly demonstrated by Forster ${ }^{(25)}$, and has been confirmed recently by Caligaries and Ateshian ${ }^{(26)}$. Furthermore, a wide range of tribological conditions were developed by specifying the relative stroke length to the contact area so that different degrees of loading and unloading of cartilage were investigated ${ }^{(27)}$. The importance of the biphasic lubrication has also been studied by chemical treatments of articular cartilage to alter the fluid pressurisation such as chondroitinase $\mathrm{ABC}^{(28-31)}$. However, the results obtained have been found to be contradictory; Pickard et al ${ }^{(28)}$ found no major differences while Kumar et al ${ }^{(29)}$ and Basalo et $\mathrm{al}^{(30,31)}$ showed a significant increase in friction. Subsequently, Katta et al ${ }^{(32)}$ showed that no difference was observed under start-up conditions while a large increase up to $50 \%$ was found under a sliding motion when the biphasic lubrication mechanism was important. The effect of collagenase enzymatic degradation on interstitial fluid pressurisation and friction was studied by Basalo et $\mathrm{al}^{(33)}$ and Naka et $\mathrm{al}^{(34)}$, respectively. Basalo et $\mathrm{al}^{(33)}$ found that the fluid load support was significantly reduced, following enzymatic treatment. However, Naka et $\mathrm{al}^{(34)}$ only found that the friction was gradually increased, after decreased at the 
beginning of sliding, compared with the normal specimens. The reduction of the initial friction was explained from the measurements of increased water content and a decrease in glycosaminoglycans (GAGs). Furthermore, damaged cartilage models through roughening with a standard-grade emery paper showed a higher level of friction ${ }^{(27)}$. Removal of the superficial zone $(\sim 100 \mu \mathrm{m})$ was not found to cause any increase in friction, however the friction in the microtomed deep zone was shown to decrease ${ }^{(35)}$.

A number of recent studies have independently identified a surface layer on cartilage surface. Kobayashi et $\mathrm{al}^{(36,37)}$ have found a "surface amorphous layer" on the cartilage surface using a cryo-scanning electron microscope. These authors further suggested that this "amorphous layer", from 2 to $200 \mu \mathrm{m}$ thick, mainly consisted of proteoglycan molecules, which is different from the superficial layer of articular cartilage which mainly consists of a collagen-fibril network and chondrocytes. They also described this layer as being able to expand and diminish rapidly and independently of the underlying collagen matrix, following loading and subsequent load removal, implying the layer's high permeability. Similar observations were made by Sasada ${ }^{(38)}$, Ikeuchi and $\mathrm{Oka}^{(39)}$, Sawae and Murakami ${ }^{(40)}$, Kumar et $\mathrm{al}^{(29)}$ and Crockett et $\mathrm{al}^{(41)}$, but these authors called this layer "gel layer", in which the condroitin- or keratan sulphates composing the leafs of the proteoglycan subunit are hydrated. Such a biphasic amorphous surface layer has been shown to significantly enhance the fluid load support and reduce friction accordingly ${ }^{(42)}$. Furthermore, removal of the surface layer was found not to change the friction due to the regeneration and replenishment of GAGs, mainly as a result of mechanical action ${ }^{(43)}$.

\subsection{Tribology of Cartilage Substitution Therapies}

Therapeutic injections of hyaluronic acid (HA), as part of "viscosupplementation" treatments, have been introduced to treat early stage osteoarthritis. Tribological studies of these therapeutic lubricant injections are, however, rather limited. Mabuchi et $\mathrm{al}^{(44)}$ found that HA was effective when the cartilage surface was washed with saline, however, the molecular weight of the HA used was found to have a negligible influence on the friction. This was explained by the non-Newtonian shear thinning characteristics of HA, and the high shear rates experienced at the articulating surfaces. Bell et $\mathrm{al}^{(27)}$ showed that hyaluronic acid was only effective in reducing friction under the conditions when the biphasic lubrication was depleted, such as at start-up. This was further demonstrated by Forsey et $\mathrm{al}^{(45)}$, who used damaged human cartilage specimens (osteoarthritis). In addition, a similar effect was observed with the introduction of dipalmitoyl phosphatidylcholine (DPCC) with sufficient concentration and further benefit was achieved with the combination of HA and DPPC. Furthermore, removal of lipids and proteins were found to increase friction only slightly $^{(46)}$. Other potential therapeutic lubricants include self-assembling peptides ${ }^{(47)}$.

Hemi-arthroplasty has been used clinically for many decades, including stemmed metallic femoral heads such as Moore and Thompson prostheses, and more recently metallic resurfacing heads ${ }^{(48)}$. However, a metallic head which articulates with acetabular cartilage has been frequently reported to lead to cartilage degeneration, and therefore, the use of alternative cartilage substitution materials becomes necessary. While theoretically lower modulus single phasic materials can promote fluid film lubrication ${ }^{(49,50)}$ as with a "cushion form" bearing, however, these essentially only produce low friction under periods of continuous motion and dynamic loading. Different biomaterials have been investigated for potential use for hemiarthroplasty, including single phasic materials such as cobalt chromium alloy $^{(51)}$, ceramic $^{(52)}$ and polyurethane ${ }^{(53)}$ as well as biphasic hydrogels such as water swollen polyhydroxyalkacrylic ${ }^{(54)}$, PVA $^{(55)}$, semi-interpenetrating network methacrylate $^{(56)}$ and methyl methacrylate $\operatorname{acid}^{(57)}$. Friction of these biomaterials against articular cartilage is mainly governed by the biphasic characteristics of the bearing surfaces discussed in Section 3.1.2, with hydrogels producing friction closest to cartilage. 


\subsection{Tribology of Artificial Hip Joint Replacements}

Extensive wear studies have been conducted on artificial hip joints due to the clinical relevance of wear debris induced adverse tissue reactions, osteolysis and loosening ${ }^{(1)}$. The vast majority of these studies to evaluate the wear performance of hip prostheses have simply measured the volumetric wear rate, and very few groups have investigated the characteristics of the wear particles generated in in-vitro simulations. Even fewer groups have combined the tribological studies of wear debris with the cellular response to prosthetic wear particles. Fisher et al ${ }^{(58)}$ introduced a relative index of specific biological activity (SBA) per unit volume of wear, and a functional biological activity (FBA), defined as the product of volumetric wear and SBA. Such a combined tribology and biology methodology has been extensively used to evaluate and compare different bearings for artificial hip joints ${ }^{(59)}$.

Friction and lubrication are often considered, along with wear, in order to understand the wear mechanism, so that wear particle generation can be minimised. Friction is usually measured to determine the lubrication regime ${ }^{(60)}$. Lubrication can be studied either experimentally using an electrical resistance technique ${ }^{(61)}$ or theoretically ${ }^{(62)}$. Laboratory wear simulation includes an array of testing, from simple hip simulators with only one loading and one motion, to full hip simulators consisting of a three dimensional physiological load and motion, determined from normal gait cycles, with varying degrees of complexity ${ }^{(63)}$.

\subsubsection{Cross-linked UHMWPE}

There has been significant interest recently in the wear of hip implants employing highly cross-linked polyethylene cups. A remarkable reduction in wear volume has often been observed in simulator studies of these materials. However, the amount of wear reduction appears to be dependent on cross-linking, kinematics, counterface roughness and bovine serum concentration. An eight fold reduction in the volumetric wear rate of the highly cross-linked polyethylene was measured, as compared to conventional polyethylene ${ }^{(64,65)}$. These findings are consistent with recent retrieval studies ${ }^{(66,67)}$. These clinical findings differ from other studies which have shown zero wear and the retention of machining marks on the polyethylene ${ }^{(68,69)}$. The use of ceramic femoral heads reduced the wear of conventional polyethylene by $35 \%$ and highly cross-linked polyethylene by $40 \%{ }^{(59)}$. However, the highly cross-linked (higher molecular weight) polyethylene produced smaller wear debris, with a larger proportion of its volume in the submicron size range, making it more biologically active than the conventional polyethylene wear debris ${ }^{(64,65)}$. The SBA of the highly cross-linked polyethylene was close to twice that of the conventional polyethylene, however, the reduction in wear rate of the highly cross-linked polyethylene was sufficient to produce a four-fold lower FBA value, compared to the conventional polyethylene ${ }^{(59)}$. Studies of $36 \mathrm{~mm}$ diameter heads against highly cross-linked polyethylene cups (10 MRad E beam) showed a higher wear rate of $10.6 \pm 1.4 \mathrm{~mm}^{3} /$ million cycles, more than twice the value found for $28 \mathrm{~mm}$ diameter heads ${ }^{(59)}$. Therefore, the use of highly cross-linked polyethylene in large diameter bearings is called into question ${ }^{(68)}$.

\subsubsection{Ceramic-on-ceramic}

Alumina ceramic on ceramic bearings with a $28 \mathrm{~mm}$ diameter have a wear rate of less than $0.1 \mathrm{~mm}^{3} /$ million cycles under standard simulator conditions, which is 50 -fold lower than highly cross-linked polyethylene and 350 times lower than standard polyethylene ${ }^{(59)}$. However, standard simulator conditions have not been found to replicate the stripe wear observed on the head of retrievals ${ }^{(70)}$, which is thought to be related to head and cup rim contact after microseparation in the swing phase. Simulation of microseparation in the hip simulator has replicated the stripe wear observed on retrievals and produced a steady state 
wear rate of $1.4 \pm 0.2 \mathrm{~mm}^{3} /$ million cycles ${ }^{(71)}$. Analysis of the wear debris from the microseparation simulations has also shown a bimodal size distribution, which is consistent with retrieval studies ${ }^{(72)}$. Nanometer size debris was identified from the normal articulation surfaces, with larger micron size granules resulting from grain boundary failure, and pull out from the stripe wear area ${ }^{(73)}$. Cell culture studies showed the alumina debris produced from microseparation simulation studies to be less reactive than conventional and cross-linked polyethylene debris with a SBA of $0.18^{(59)}$. This, when combined with the reduced wear volume, results in a substantially reduced FBA, which is almost 20 times lower than that predicted for highly cross-linked polyethylene, and 80 times lower than conventional polyethylene.

\subsubsection{Metal-on-metal}

Tribology of metal-on-metal (MOM) bearings for artificial hip joints is quite complex. It is generally accepted that a mixed lubrication regime exists in MOM bearings. Therefore, wear of this type of hard-on-hard bearing not only depends on the metallic materials, but also the lubrication regime. Two distinct wear phases are generally observed, the initial running-in phase with a relatively high wear rate, followed by a steady-state phase, with a much reduced wear rate. It is generally accepted that high carbon $(>0.2 \%)$ cobalt chromium alloy should be used, and differences in either cast or wrought, or processing routes such as hot iso-static pressing and solution annealing or as cast do not appear to make a significant difference in the wear of MOM bearings ${ }^{(74-76)}$. Boundary lubrication can influence the wear of MOM bearings, and the concentration of bovine serum can be important. However, only a small influence has been shown in a recent review by Scholes and Unsworth ${ }^{(77)}$. An increase in serum concentration appears to reduce both friction and wear, as a result of improved boundary lubrication. However, no well controlled and directly comparative studies appear to have been undertaken, and the effect of serum concentration can often be masked by other parameters. More important are the design and loading parameters, which can influence fluid film lubrication, and consequently significantly wear. For example, an increase in the applied swing phase load has been shown to produce higher wear in MOM bearings ${ }^{(78)}$. The elevated wear with elevated swing phase load has been also associated with an elevated coefficient of friction. These changes in friction and wear with increased swing phase load are indicative of a reduction in fluid film lubrication ${ }^{(79)}$. Wear of MOM bearings reduces as the head diameter increases from $28 \mathrm{~mm}^{(59,80,81)}$. These observations are consistent with theoretical lubrication analysis ${ }^{(82)}$, since increase in head size not only increases the effective radius but also the sliding velocity. An increase in the radial clearance increases the wear in MOM bearings, due to depleted fluid film lubrication. This is particularly important for large diameter MOM bearings for hip resurfacing prostheses, since an excessive clearance, coupled with the large diameter, can significantly increase the sliding distance, and adversely elevate wear. Metallic cobalt chromium wear particles have been found to be in the nanometer size range (mean size $28 \mathrm{~nm}$ ), and cytotoxic to cells at concentrations of $5 \mu \mathrm{m}^{3}$ per cell and greater ${ }^{(83)}$. As a result of the effect of metal ions on macrophages, metallic particles do not stimulate an inflammatory response in the same way as polyethylene particles. The cytotoxic effect of the metallic debris remains a clinical concern $^{(84)}$ and has been a substantial factor in seeking a reduction in the volume of metal wear and reduction in ion levels.

\subsubsection{Ceramic-on-metal and Surface engineered coatings}

Ceramic on metal bearings have been studied by Firkins et $\mathrm{al}^{(85)}$ and the wear was found to be one hundred-fold lower than with MOM bearings (28 mm diameter). Such a wear reduction with the ceramic on metal bearings has been attributed to the differential hardness of the bearing surfaces, smoother surfaces, improved lubrication, and a reduction in 
corrosive wear.

Surface engineered coatings have also been introduced to reduce wear further in MOM bearings ${ }^{(86)}$. For example, the wear of thick $\mathrm{CrCN}$ bearings $(>10 \mu \mathrm{m})$ has shown a highly significant 100 -fold reduction in wear, compared to standard MOM bearings ${ }^{(86,87)}$. The wear debris from $\mathrm{CrCN}$ has been found to be more biocompatible and less cytotoxic than the metallic debris ${ }^{(88)}$.

\subsection{Tribology of Tissue Engineered Cartilage}

Tissue engineering of articular cartilage has been developed extensively in the last five to ten years. However, it is only recently that the functional requirements of tissue engineered cartilage have been addressed, such as tribological characteristics. A number of centres have investigated the friction of tissue engineered articular cartilage ${ }^{(89-91)}$ and the boundary lubricating properties of lubricin ${ }^{(92-93)}$. Generally, the friction of tissue engineered cartilage has been found to rise more quickly with loading time, than natural articular cartilage. This is consistent with poor mechanical and biphasic properties of tissue engineered cartilage.

\section{Discussion}

Lubrication studies of the natural hip joint are initially driven by the need to understand the remarkable tribological functions and failures of these natural bearings. Success of end-stage total hip joint replacements has helped millions of people suffering from joint diseases and trauma. Coupled studies of the tribology of the bearing surfaces and biological reactions to wear debris have contributed to such successes. However, the limitation of end-stage hip joint replacements means that alternative more conservative therapies are required for younger and more active patients. This has introduced new challenges in the tribological methodologies and biological considerations, and also the need to better understand the tribology of natural hip joints. Integration of individual studies of friction, wear and lubrication, coupled with biological considerations, are vital in the understanding of the tribology of hip joints and the design and optimisation of existing and future therapeutic interventions.

\section{References}

(1) Ingham, E. and Fisher, J., The Role of Macrophages in Osteolysis of Total Joint Replacement, Biomaterials, Vol., 26, No. 11(2005), pp.1271-1286.

(2) Villar, R., Resurfacing Arthroplasty of the Hip, J Bone Joint Surg Br, Vol. 86, No. 2 (2004), pp.157-158.

(3) Jacobs, J.J., Hallab, N.J., Skipor, A.K. and Urban, R.M., Metal Degradation Products: a Cause for Concern in Metal-Metal Bearings?, Clin Orthop Relat Res., Vol. 417 (2003), pp.139-147.

(4) Sharma, B. and Elisseeff, J.H., Engineering Structurally Organized Cartilage and Bone Tissues, Annals of Biomedical Engineering, Vol. 32, No. 1 (2004), pp.148-159

(5) Aoki, H., Tomita, N., Harada, Y., Hattori, K., Sonobe, M. and Suguro, T., The Report of the Cartilage Regeneration using Total Joint Regeneration System (Internal-Fixator Type), Biomed Mater Eng., Vol. 13, No. 4 (2003), pp. 411-417.

(6) Wimmer, M.A., Grad, S., Kaup, T., Hanni, M., Schneider, E., Gogolewski, S. and Alini, M., Tribology Approach to the Engineering and Study of Articular Cartilage, Tissue Eng., Vol. 10, No. 9-10 (2004), pp.1436-1445.

(7) Hunter, W., Of the Structure and Diseases of Articulating Cartilages, Phi. Trans. Roy., Vol. 42, (1743), p. 514

(8) Unsworth, A., Tribology of Human and Artificial Joints, Proc Inst Mech Eng [H], Vol. 205, No. 3 (1991), pp. 163-172.

(9) Dowson, D. and Jin, Z.M., Micro-Elastohydrodynamic Lubrication of Synovial Joints, 
Engineering in Medicine, Vol. 15 (1986), pp.63-65.

(10) Hills, B.A., Boundary Lubrication in Vivo, Proc Inst Mech Eng [H]., Vol. 214, No. 1 (2000), pp. 83-94.

(11) Elsaid, K.A., Jay, G.D., Warman, M.L., Rhee, D.K. and Chichester, C.O., Association of Articular Cartilage Degradation and Loss of Boundary-lubricating Ability of Synovial Fluid Following Injury and Inflammatory Arthritis, Arthritis Rheum., Vol. 52, No. 6 (2005), pp. 1746-1755.

(12) Mow, V.C., Ateshian, G.A. and Spilker, R.L., Biomechanics of Diarthrodial Joints: a Review of Twenty Years of Progress, J Biomech Eng., Vol. 115, No. 4B (1993), pp. 460-467.

(13) Murakami, T., Higaki, H., Sawae, Y., Ohtsuki, N., Moriyama, S. and Nakanishi, Y., Adaptive Multimode Lubrication in Natural Synovial Joints and Artificial Joints, Proc Inst Mech Eng [H], Vol. 212, No. 1(1998), pp.23-35.

(14) McCutchen, C.W., The Frictional Properties of Animal Joints, Wear, Vol.5, (1962), pp.1-17.

(15) Walker, P.S., Dowson, D., Longfield, M.D. and Wright, V., Boosted Lubrication in Synovial Joints by Fluid Entrapment and Enrichment, Ann. Rheum. Dis., Vol. 27, No. 6(1968), pp.512-520.

(16) Mow, V.C. and Lai, W.L., Recent Developments in Synovial Joint Biomechanics, SIAM Review, Vol. 22, No. 3(1980), pp. 275-317.

(17) Forster, H, and Fisher, J., The influence of Loading Time and Lubricant on the Friction of Articular Cartilage, Proc Inst Mech Eng [H]., Vol. 210 (1996), pp.109-119.

(18) Ateshian, G.A., A Theoretical Formulation for Boundary Friction in Articular Cartilage, J Biomech Eng., Vol. 119, No. 1(1997), pp.81-6.

(19) Soltz, M.A. and Ateshian, G.A., Experimental Verification and Theoretical Prediction of Cartilage Interstitial Fluid Pressurization at an Impermeable Contact Interface in Confined Compression, J Biomech., Vol. 31, No. 10 (1998), pp.927-34.

(20) Forster, H. and Fisher, J., The Influence of Continuous Sliding and Subsequent Surface Wear on the Friction of Articular Cartilage, Proc Inst Mech Eng [H], Vol. 213, No. 4 (1999), pp.329-345.

(21) Mabuchi, K., Ujihira, M. and Sasada, T., Influence of Loading Duration on the Start-up Friction in Synovial Joints: Measurements using a Robotic System, Clin Biomech., Vol. 13, No. 7 (1998), pp. 492-494.

(22) Morrell, K.C., Hodge, W.A., Krebs, D.E. and Mann, R.W., Corroboration of in Vivo Cartilage Pressures with Implications for Synovial Joint Tribology and Osteoarthritis Causation, Proc Natl Acad Sci USA, Vol. 11, No. 102(41) (2005), pp. 14819-14824.

(23) Krishnan, R., Park, S., Eckstein, F. and Ateshian, G.A., Inhomogeneous Cartilage Properties Enhance Superficial Interstitial Fluid Support and Frictional Properties, but Do Not Provide a Homogeneous State of Stress, J Biomech Eng., Vol. 125, No. 5 (2003), pp. 569-577.

(24) Krishnan, R., Mariner, E.N. and Ateshian, G.A., Effect of Dynamic Loading on the Frictional Response of Bovine Articular Cartilage, J Biomech., Vol. 38, No. 8 (2005), pp.1665-1673.

(25) Forster, H., Mixed and Boundary Lubrication in Natural Synovial Joints, PhD Thesis, University of Leeds, 1996.

(26) Caligaris, M. and Ateshian, G., Migrating Articular Contact Areas Promote Sustainable Low Friction Coefficients, Transactions of Orthopaedic Research Society, Chicago, IL, Vol.31 (2006), 0083.

(27) Bell, C.J., Ingham, E. and Fisher, J., Influence of Hyaluronic Acid on the Time-dependent Friction Response of Articular Cartilage under Different Conditions, Proc Inst Mech Eng [H]., Vol. 220, No. 1 (2006), pp.23-31.

(28) Pickard, J.E., Ingham, E., Egan, J. and Fisher, J., Investigation into the Effect of Proteoglycan Molecules on the Tribological Properties of Cartilage Joint Tissues, Proc Inst Mech Eng [H]., Vol. 212, No. 3 (1998), pp.177-182. 
(29) Kumar, P., Oka, M., Toguchida, J., Kobayashi, M., Uchida, E., Nakamura, T. and Tanaka, K., Role of Uppermost Superficial Surface Layer of Articular Cartilage in the Lubrication Mechanism of Joints, J Anat., Vol. 199, Pt. 3 (2001), pp. 241-250.

(30) Basalo, I.M., Raj, D., Krishnan, R., Chen, F.H., Hung, C.T. and Ateshian, G.A., Effects of Enzymatic Degradation on the Frictional Response of Articular Cartilage in Stress Relaxation, J Biomech., Vol. 38, No 6 (2005), pp.1343-9.

(31) Basalo, I.M., Chen, F.H., Hung, C.T. and Ateshian, G.A., Frictional Response of Bovine Articular Cartilage under Creep Loading Following Proteoglycan Digestion with Chondroitinase ABC, J Biomech Eng., Vol. 128, No. 1 (2006), pp.131-134.

(32) Katta, J., Jin, Z.M., Ingham, E. and Fisher, J., Effect of Glycosaminoglycan (GAG) Depletion on Cartilage Friction under Various Tribological Conditions, Abstracts of the 5th World Congress of Biomechanics, Munich, Germany, 4862.

(33) Basalo, I.M., Mauck, R.L., Kelly, T.A., Nicoll, S.B., Chen, F.H., Hung, C.T. and Ateshian, G.A., Cartilage Interstitial Fluid Load Support in Unconfined Compression Following Enzymatic Digestion, J Biomech Eng., Vol. 126, No. 6 (2004), pp. 779-786.

(34) Naka, M.H., Hattori, K., Ohashi, T. and Ikeuchi, K., Evaluation of the Effect of Collagen Network Degradation on the Frictional Characteristics of Articular Cartilage using a Simultaneous Analysis of the Contact Condition, Clin Biomech, Vol. 20, No. 10 (2005), pp.1111-1118.

(35) Krishnan, R., Caligaris, M., Mauck, R.L., Hung, C.T., Costa, K.D. and Ateshian, G.A., Removal of the Superficial Zone of Bovine Articular Cartilage Does not Increase its Frictional Coefficient, Osteoarthritis Cartilage, Vol. 12, No. 12 (2004), pp.947-955.

(36) Kobayashi, S., Yonekubo, S. and Kurogouchi, Y., Cryoscanning Electron Microscopic Study of the Surface Amorphous Layer of Articular Cartilage, J Anat., Vol. 187, Pt 2 (1995), pp. 429-444.

(37) Kobayashi, S., Yonekubo, S. and Kurogouchi,Y., Cryoscanning Electron Microscopy of Loaded Articular Cartilage with Special Reference to the Surface Amorphous Layer, J Anat., Vol. 188, Pt 2 (1996), pp. 311-322.

(38) Sasada, T., Lubrication of Human Joints - Nature of Joint Friction and "Surface Gel Hydration Lubrication", Proc. of 26th Annual Meeting of the Japanese Society for Clinical Biomechanics and Related Research, Kyoto, 1999, 40.

(39) Ikeuchi, K. and Oka, M., The Joint Lubrication with Water in Articular Cartilage, Proc. of 26th Annual Meeting of the Japanese Society for Clinical Biomechanics and Related Research, Kyoto, 1999, 43.

(40) Sawae, Y. and Murakami, T., Surface Layer of Articular Cartilage Observed by Atomic Force Microscopy in Liquid - Morphology and Role in Joint Lubrication, Proc. of 26th Annual Meeting of the Japanese Society for Clinical Biomechanics and Related Research, Kyoto, 1999, 46.

(41) Crockett, R., Roos, S., Rossbach, P., Dora, C., Born, W. and Troxler, H., Imaging of the Surface of Human and Bovine Articular Cartilage with ESEM and AFM, Tribology Letter, Vol. 19, No.4 (2005), pp.311-317.

(42) Graindorge, S., Ferrandez, W., Jin, Z.M., Fisher, J., Ingham, E., Grant, C. and Twigg, P., Biphasic Surface Amorphous Layer Lubrication of Articular Cartilage, Medical Engineering and Physics, Vol. 27, No. 10 (2005), pp. 836-844

(43) Graindorge, S., Ferrandez, W., Ingham, E., Jin, Z.M. and Fisher, J., The Role of the Surface Amorphous Layer of Articular Cartilage in Joint Lubrication, Proc Inst Mech Eng [H]., Vol. 220, No. 5 (2006), pp.597-607.

(44) Mabuchi, K., Obara, T., Ikegami, K., Yamaguchi, T. and Kanayama, T., Molecular Weight Independence of the Effect of Additive Hyaluronic Acid on the Lubricating Characteristics in Synovial Joints with Experimental Deterioration, Clin Biomech., Vol. 14, No. 5 (1999), pp.352-356. 
(45) Forsey, R.W., Fisher, J., Thompson, J., Stone, M.H., Bell, C. and Ingham, E., The Effect of Hyaluronic Acid and Phospholipid Based Lubricants on Friction within a Human Cartilage Damage Model, Biomaterials, Vol. 27, No. 26 (2006), pp.4581-4590.

(46) Pickard, J.E., Fisher, J., Ingham, E. and Egan, J., Investigation into the Effects of Proteins and Lipids on the Frictional Properties of Articular Cartilage, Biomaterials, Vol. 19, No. 19 (1998), pp.1807-1812.

(47) Bell, C.J., Carrick, L.M., Katta, J., Jin, Z., Ingham, E., Aggeli, A., Boden, N., Waigh, T.A. and Fisher, J., Self-assembling Peptides as Injectable Lubricants for Osteoarthritis, J Biomed Mater Res A., Vol. 78, No. 2 (2006), pp.236-246.

(48) Beaule, P.E., LeDuff, M. and Amstutz, H.C., Hemiresurfacing Arthroplasty of the Hip for Failed Free-vascularized Fibular Graft, J Arthroplasty, Vol. 18, No. 4 (2003), pp.519-523.

(49) Bigsby, R.J., Auger, D.D., Jin, Z.M., Dowson, D., Hardaker, C.S. and Fisher, J., A Comparative Tribological Study of the Wear of Composite Cushion Cups in a Physiological Hip Joint Simulator, J Biomech., Vol. 31, No. 4 (1988), pp.363-369.

(50) Scholes, S.C., Burgess, I.C., Marsden, H.R., Unsworth, A., Jones, E. and Smith, N., Compliant Layer Acetabular Cups: Friction Testing of a Range of Materials and Designs for a New Generation of Prosthesis that Mimics the Natural Joint, Proc Inst Mech Eng [H], Vol. 220, No.5 (2006), pp. $583-596$

(51) Siguier, T., Siguier, M., Judet, T., Charnley, G. and Brumpt, B., Partial Resurfacing Arthroplasty of the Femoral Head in Avascular Necrosis. Methods, Indications, and Results, Clin Orthop Relat Res., Vol. 386 (2001), pp.85-92.

(52) Degreif, J., Muller, L.P., Runkel, M., Blum, J. and Willmann, G., Long-term Results after Operative Treatment of Femoral Neck Fractures with Ceramic Head Prostheses, Orthopedics, Vol. 24, No. 2 (2001), pp.129-133.

(53) Jennings, L.M. and Fisher, J., A Biomechanical and Tribological Investigation of a Novel Compliant All Polyurethane Acetabular Resurfacing System, Proc. Int. Conf. Engineers and Surgeons Joined at the Hip, IMechE, (2002), C601/032/.

(54) McCutchen, C. W., In 'Lubrication and Wear in Joints' (Ed, Wright, V.), Sector, (1969), pp. 117-123.

(55) Ushio, K,, Oka, M., Hyon, S.H., Yura, S., Toguchida, J. and Nakamura, T., Partial Hemiarthroplasty for the Treatment of Osteonecrosis of the Femoral Head. An Experimental Study in the Dog, J Bone Joint Surg Br., Vol. 85, No. 6 (2003), pp.922-930.

(56) Caravia, L, Dowson, D and Fisher, J., A Comparison of Friction in Hydrogel and Polyurethane Materials for Cushion-form Joints, Journal of Materials: Materials in Medicine, Vol. 4, (1993), pp.515-520.

(57) Northwood, E. and Fisher, J. Investigation of the Friction and Surface Degradation of Innovative Chondroplasty Materials Against Articular Cartilage, Proc Inst Mech Eng [H], submitted.

(58) Fisher, J., Bell, J., Barbour, P.S.M., Tipper, J.L., Matthews, J.B., Besong, A.A., Stone, M.H. and Ingham, E., A Novel Method for the Prediction of Functional Biological Activity of Polyethylene Wear Debris. Proc Inst Mech Eng [H], Vo. 215, No. 2 (2001), pp.127-132.

(59) Fisher, J., Jin, Z.M., Tipper, J., Stone, M. and Ingham, E., Tribology of Alternative Bearings, Clin Orthop Relat Res., (2006), in press.

(60) Scholes, S.C. and Unsworth, A., Comparison of Friction and Lubrication of Different Hip Prostheses, Proc. Instn. Mech. Engrs., J. Eng. in Med., Vol. 214, No. 1 (2000), pp.49-57.

(61) Dowson, D., McNie, C.M. and Goldsmith, A.A.J., Direct Experimental Evidence of Lubrication in a Metal-on-metal Total Hip Replacement Tested in a Joint Simulator, Proc. Instn. Mech. Engrs., J. Mech. Eng. Sci., Vol. 214, (2000), pp.75-86.

(62) Liu, F., Jin, Z.M., Hirt, F., Rieker, C., Roberts, P. and Grigoris, P., Transient Elastohydrodynamic Lubrication Analysis of Metal-on-metal Hip Implant Under Simulated Walking Conditions, J Biomech., Vol. 39, (2005), pp.905-914 
(63) Saikko, V., A 12-station Anatomic Hip Joint Simulator, Proc Inst Mech Eng [H]., Vol. 219, No. 6 (2005), pp.437-448.

(64) Endo, M., Tipper, J.L., Barton, D.C., Stone, M.H., Ingham, E. and Fisher, J., Comparison of Wear, Wear debris and Functional Biological Activity of Moderately Crosslinked and Non-crosslinked Polyethylene in Hip Prostheses. Proc Inst Mech Eng [H], Vol. 216, (2002), pp.111-122.

(65) Galvin, A.L., Tipper, J.L., Ingham, E. and Fisher, J., Nanometre Size Wear Debris Generated from Crosslinked and Non-crosslinked Ultra High Molecular Weight Polyethylene in Artificial Joints, Wear, Vol. 259, (2005), pp.977-983

(66) Martell, J.M., Verner, J.J. and Incavo, S.J., Clinical Performance of a Highly Cross-linked Polyethylene at Two Years in Total Hip Arthroplasty: A Randomized Prospective Trial, J Arthroplasty, Vol. 18, (2003), pp.55-60.

(67) Bradford, L., Baker, D.A., Graham, J., Ries, M. and Pruitt, L.A., Wear and Surface Cracking in Early Retrieved Highly Crosslinked Polyethylene Acetabular Liners, J Bone Joint Surg Am., Vol. 86, (2004), pp.1271-1282.

(68) Muratoglu, O.R., Bragdon, C.R., O'Connor, D.O., Perinchief, R.S., Estok, II D.M., Jasty, M. and Harris, W.H., Larger Diameter Femoral Heads Used in Conjunction with a Highly Cross-linked Ultra-high Molecular Weight Polyethylene, J Arthroplasty, Vol. 16, (2001), pp.24-30.

(69) D'Lima, D.D., Hermida, J.C., Chen, P.C. and Colwell, C.W. Jr., Polyethylene Cross-linking by Two Different Methods Reduces Acetabular Liner Wear in a Hip Joint Wear Simulator. J. Orthop Res., Vol. 21, (2003), pp.761-766.

(70) Nevelos, J., Ingham, E., Doyle, C., Streicher, R., Nevelos, A., Walter, W. and Fisher, J., Microseparation of the Centers of Alumina-alumna Artificial Hip Joints During Simulator Testing Produces Clinically Relevant Wear and Patterns, J Arthroplasty, Vol. 15, No.6 (2000), pp.793-795.

(71) Stewart, T., Tipper, J.L., Streicher, R., Ingham, E. and Fisher, J., Long-term Wear or HIPed Alumina on Alumina Bearings for THR under Microseparation Conditions. J Mater Sci Mater Med., Vol. 12, (2001), pp.1053-1056.

(72) Hatton, A., Nevelos, J.E., Nevelos, A.A., Banks, R.E., Fisher, J. and Ingham, E., Alumina-alumina Artificial Hip Joints. Part I : A Histological Analysis and Characterisation of Wear Debris by Laser Capture Microdissection of Tissues Retrieved at Revision, Biomaterials, Vol. 23, (2002), pp.3429-3440.

(73) Tipper, J.L., Hatton, A., Nevelos, J.E., Ingham, E., Doyle, C., Streicher, R., Nevelos, A.B. and Fisher, J., Alumina-alumina Artificial Hip Joints. Part II : Characterisation of the Wear Debris from in Vitro Hip Joints Simulations, Biomaterials, Vol. 23, (2002), pp.3441-3448.

(74) Chan, F.W., Bobyn, J.D., Medley, J.B., Krygier, J.J. and Tanzer, M., The Otto Aufranc Award - Wear and Lubrication of Metal-on-metal Hip Implants, Clin Orthop Relat Res., Vol.369, (1999), pp.10-24.

(75) Dowson, D., Hardaker C., et al., A Hip Joint Simulator Study of the Performance of Metal-on-metal Joints: Part I: The Role of Materials, J Arthroplasty, Vol. 19, No.8 (Supplement 3) (2004), pp.118-123.

(76) Bowsher, J.G., Nevelos, J., Williams, P.A. and Shelton, J.C., 'Severe' Wear Challenge to 'As-cast' and 'Double heat-treated' Large-diameter Metal-on-metal Hip Bearings, Proc Inst Mech Eng [H], Vol. 220, No. 2 (2006), pp.135-143.

(77) Scholes, S.C. and Unsworth, A., The Tribology of Metal-on-metal Total Hip Replacements, Proc Inst Mech Eng [H], Vol. 220, No.2 (2006), pp.183-94.

(78) Williams, S., Isaac, G., Hatto, P., Stone, M.H., Ingham. E. and Fisher, J., Comparative Wear Under Different Conditions of Surface-engineered Metal-on-metal Bearings for Total Hip Arthroplasty, J Arthroplasty, Vol. 19, No. 8(Suppl 3) (2004), pp.112-117

(79) Williams, S., Jalali-Vahid, D., Jin, Z.M., Stone, M., Ingham, E. and Fisher, J., Effect of 
Swing Phase Load on Metal-on-Metal Hip Lubrication, Friction And Wear, J Biomech., (2006), in press

(80) Dowson, D., Hardaker, C., Flett, M. and Isaac, G.H., A Hip Joint Simulator Study of the Performance of Metal-on-metal Joints: Part II: Design, J Arthroplasty, Vol. 19, No. 8 (Supplement 3) (2004), pp.124-130.

(81) Rieker, C.B., Schon, R., Konrad, R., Liebentritt, G., Gnepf, P., Shen, M., Roberts, P. and Grigoris, P., Influence of the Clearance on In-vitro Tribology of Large Diameter Metal-on-metal Articulations Pertaining to Resurfacing Hip Implants, Orthop Clin North Am, Vol. 36, No. 2 (2005), pp.135-142.

(82) Jin, Z.M., Dowson, D. and Fisher, J., Analysis of Fluid Film Lubrication in Artificial Hip Joint Replacements with Surfaces of High Elastic Modulus, Proc Inst Mech Eng [H]., Vol. 211, (1997), pp.247-256.

(83) Germain, M.A., Hatton, A., Williams, S., Matthews, J.B., Stone, M.H., Fisher, J. and Ingham, E., Comparison of the Cytotoxicity of Clinically Relevant Cobalt-chromium and Alumina Ceramic Wear Particles in Vitro, Biomaterials, Vol. 24, (2003), pp.469-479

(84) Dumbleton, J.H. and Manley, M.T., Metal-on-Metal Total Hip Replacement: What does the Literature Say? J Arthroplasty, Vol.20, No.2 (2005), pp.174-188.

(85) Firkins, P.J., Tipper, J.L., Ingham, E., Stone, M.H., Farrar, R. and Fisher, J., A Novel Low Wearing Differential Hardness, Ceramic-on-metal Hip Joint Prosthesis, J Biomech., Vol. 34, No. 10 (2001), pp.1291-1298.

(86) Fisher, J., Hu, X.Q., Tipper, J.L., Stewart, T.D., William, S., Stone, M.H., Davies, C., Hatto, P., Bolton, J., Riley, M., Hardaker, C., Isaac, G.H., Berry, G. and Ingham, E., An in Vitro Study of the Reduction in Wear of Metal-on-metal Hip Prostheses Using Surface-engineered Femoral Heads, Proc Inst Mech Eng [H], Vol. 216, No. 4 (2002), pp.219-230.

(87) Fisher, J., Hu, X.Q., Stewart, T.D., Williams, S., Tipper, J.L., Ingham, E., Stone, M.H., Davies, C., Hatto, P., Bolton, J., Riley, M., Hardaker, C., Isaac, G.H. and Berry. G., Wear of Surface Engineered Metal-on-metal Hip Prostheses, J Mater Sci Mater Med., Vol. 15, No. 3 (2004), pp.225-235.

(88) Williams, S., Tipper, J.L., Ingham, E., Stone, M.H. and Fisher, J., In vitro Analysis of the Wear, Wear Debris and Biological Activity of Surface-engineered Coatings for Use in Metal-on-metal Total Hip Replacements, Proc Inst Mech Eng [H], Vol. 217, No. 3(2003), pp.155-163.

(89) Lima, E., Bain, L.M., Serebrov, A., Mauck, R., Byers, B., Tuan, R., Ateshian, G., and Hung, C., Measuring the Frictional Properties of Tissue-Engineered Cartilage Constructs, Transactions of Orthopaedic Research Society, Chicago, IL, Vol.31, (2006), 1501.

(90) Morita, Y., Tomita, N., Aoki, H., Sonobe, M., Wakitani, S., Tamada, Y., Suguro, T. and Ikeuchi, K., Frictional Properties of Regenerated Cartilage in Vitro, J Biomech., Vol. 39, No 1, (2006), pp. 103-109.

(91) Plainfossé, M., Katta, J., Jin, Z.M., Fisher, J., Hatton, P.V. and Crawford, A., Tribology and Mechanical Properties of Tissue Engineered Cartilage Using Bovine Chondrocytes Seeded on PGA Scaffolds, $5^{\text {th }}$ UK Society of Biomaterials Conference, Manchester, UK, $28^{\text {th }}-29^{\text {th }}$ June, (2006), p.76.

(92) Grad, S., Lee, C.R., Gorna, K., Gogolewski, S., Wimmer, M.A. and Alini, M., Surface Motion Upregulates Superficial Zone Protein and Hyaluronan Production in Chondrocyte-seeded Three-dimensional Scaffolds, Tissue Eng., Vol. 11, No. 1-2 (2005), pp. 249-256.

(93) Klein, T.J., Schumacher, B.L., Blewis, M.E., Schmidt, T.A., Voegtline, M.S., Thonar, E.J., Masuda, K. and Sah, R.L., Tailoring Secretion of Proteoglycan 4 (PRG4) in Tissue-Engineered Cartilage, Tissue Eng., Vol. 12, No. 6 (2006), pp.1429-1439. 